\title{
REVIEW
}

\section{NKT cell subsets as key participants in liver physiology and pathology}

\author{
Keya Bandyopadhyay, Idania Marrero and Vipin Kumar
}

Natural killer T (NKT) cells are innate-like lymphocytes that generally recognize lipid antigens and are enriched in microvascular compartments of the liver. NKT cells can be activated by self- or microbial-lipid antigens and by signaling through toll-like receptors. Following activation, NKT cells rapidly secrete pro-inflammatory or antiinflammatory cytokines and chemokines, and thereby determine the milieu for subsequent immunity or tolerance. It is becoming clear that two different subsets of NKT cells-type I and type II-have different modes of antigen recognition and have opposing roles in inflammatory liver diseases. Here we focus mainly on the roles of both NKT cell subsets in the maintenance of immune tolerance and inflammatory diseases in liver. Furthermore, how the differential activation of type I and type II NKT cells influences other innate cells and adaptive immune cells to result in important consequences for tissue integrity is discussed. It is crucial that better reagents, including CD1d tetramers, be used in clinical studies to define the roles of NKT cells in liver diseases in patients.

Cellular \& Molecular Immunology (2016) 13, 337-346; doi:10.1038/cmi.2015.115; published online 14 March 2016

Keywords: CD1d; lipids; liver disease; NKT cells

\section{INTRODUCTION}

The liver is a specialized tissue that, owing to its anatomical location, is the first recipient of gut-derived bacteria and their products, such as lipopolysaccharides. Therefore, the hepatic immune response to such products has to be carefully regulated to avoid liver injury. Liver inflammation is an integral part of the hepatic wound-healing response to injury due to, for example, excess fat, alcohol or viruses. Controlled inflammation may be beneficial in the short term in terms of the promotion of regeneration or an effective immune response against pathogens. However, chronic inflammation and the associated regenerative wound-healing response are strongly linked to the development of fibrosis, cirrhosis and cancer. ${ }^{1}$ Compared with other peripheral organs, the liver is enriched in a number of innate immune cells, including resident macrophages, Kupffer cells (KCs), dendritic cells (DCs), natural killer (NK) cells and NK T (NKT) cells. ${ }^{2,3}$ NKT cells are particularly enriched in the murine liver and form an important nexus that connects innate and adaptive immunities; these cells therefore have a crucial role in setting up the inflammatory response. Because the two NKT cell subsets can have opposing roles in immune responses that are mediated by the secretion of both pro-inflammatory and anti-inflammatory cytokines, it is necessary to distinguish their roles in acute and chronic inflammatory conditions of the liver, such as alcoholic hepatitis, autoimmune hepatitis (AIH) and steatohepatitis. In this review, we discuss the current knowledge about the roles of the two major subsets of NKT cells in inflammatory liver diseases and the maintenance of immune tolerance.

\section{TWO MAJOR SUBSETS OF NKT CELLS IN THE LIVER}

NKT cells are innate-like T cells that express TCR- $\alpha \beta$ chains in addition to the typical NK cell markers and have an important immunoregulatory role in inflammatory conditions, including autoimmune diseases, infectious diseases and cancer. ${ }^{4-6}$ NKT cells act as a bridging system between innate and adaptive immunities. ${ }^{7}$ These cells can recognize both exogenous and endogenous lipid antigens in the context of the major histocompatibility complex-like molecule CD1d. ${ }^{8-10}$ Studies using knock-in Cxcr6 ${ }^{\mathrm{gfp} /+}$ mice have demonstrated that type I NKT cells migrate to the liver sinusoids within minutes of $\alpha$ galactosylceramide ( $\alpha \mathrm{GalCer}$ ) injection. ${ }^{11,12}$ The enrichment and constitutive activation of NKT cells in the liver sinusoids indicate that these cells participate in the mechanisms that

Department of Medicine, University of California San Diego, La Jolla, CA 92037, USA

Correspondence: Professor V Kumar, MS, PhD, Department of Medicine, University of California San Diego, 9500 Gilman Drive, \#0637, La Jolla, CA 92037, USA.

E-mail: vckumar@ucsd.edu

Received: 3 November 2015; Revised: 19 December 2015; Accepted: 23 December 2015 
control the induction and/or prevention of inflammation in the liver in various immunological responses. ${ }^{4,13,14}$

CD1d-restricted NKT cells are classified into two main subsets, that is, type I or invariant NKT cells and type II or diverse NKT cells. Type I NKT cells are more prevalent than type II NKT cells in mice and comprise $\sim 50 \%$ of murine intrahepatic lymphocytes. ${ }^{4,15-17}$ Type I NKT cells express a conserved semi-invariant $\alpha \beta$ TCR that is encoded predominantly by a germ line $V \alpha$ gene (V $\alpha 24$ in humans and $V \alpha 14$ in mice) and J $\alpha 18$ gene segments paired with a more diverse set of non-germ line $\mathrm{V} \beta$ genes $(\mathrm{V} \beta 8.2, \mathrm{~V} \beta 7$, or $\mathrm{V} \beta 2$ in mice and $\mathrm{V} \beta 11$ in humans). ${ }^{18}$ In humans, type I NKT cells comprise $~ 0.1-1 \%$ of the circulating T cells. CD4- and CD4+ type I NKT cells predominantly secrete Th1- and Th2-type cytokines, respectively, and Th1-like CD8 $\alpha+$ type I NKT cells have also been described.

Type II NKT cells are more abundant than type I cells in humans, and as in mice, they express relatively diverse TCR- $\alpha$ and TCR- $\beta$ chains. Recently, we demonstrated that one major subset of type II NKT cells that is reactive to the $\beta$-linked self-glycolipid sulfatide expresses an oligoclonal TCR repertoire that predominant uses the $\mathrm{V} \alpha 3 / \mathrm{V} \alpha 1-\mathrm{J} \alpha 7 / \mathrm{J} \alpha 9$ and $\mathrm{V} \beta 8.1 / \mathrm{V} \beta 3.1$ J $\beta 2.7$ gene segments. ${ }^{19}$ Recent insights derived from the crystal structures of a type I NKT cell TCR- $\alpha$ GalCer/CD1d complex and a type II NKT cell TCR-sulfatide/CD1d complex suggest that distinct molecular motifs act in TCR recognition by type I and type II NKT cells. ${ }^{21-23}$ The type I NKT TCR binds to CD1d in a parallel configuration that mainly involves the $\alpha$-chain. The crucial residues within the CDR2 $\beta, \operatorname{CDR} 3 \alpha$ and CDR1 $\alpha$ loops of the semi-invariant TCR of type I NKT cells have been demonstrated to be involved in the recognition of the $\alpha \mathrm{GalCer} / \mathrm{CD} 1 \mathrm{~d}$ complex. ${ }^{24}$ In contrast, the sulfatidereactive type II NKT TCR binds its ligands primarily with its $\beta$-chain by pinning them against the CD1d surface.

\section{ANTIGEN RECOGNITION AND ACTIVATION OF TYPE I NKT CELLS}

Type I NKT cells were initially characterized as a major subset in mice that are reactive to a marine sponge-derived glycolipid $\alpha$ GalCer; this glycolipid stimulates these mice like a superantigen in that it binds with high affinity to CD1d and type I NKT TCRs. ${ }^{25}$ However, other glycolipids, such as isoglobotrihexosylceramide, are also able to activate type I NKT cells in a CD1d-dependent manner, but none of them are as effective as $\alpha$ GalCer. ${ }^{27-30}$ In addition to lipid antigens, type I NKT cells are also activated following toll-like receptor (TLR)-mediated signaling and/or by cytokines (interleukin (IL)-12, IL-18 or type I interferon (IFN)) secreted by activated antigenpresenting cells (APC), such as KCs, hepatocytes and myeloid DCs. ${ }^{31}$ Following activation, type I NKT cells can secrete Th1-, Th2- or Th17-like cytokines. Thus, depending upon the tissue milieu, antigen-presenting cell and lipid antigen, type I NKT cells can secrete different cytokine profiles. For example, type I NKT cells predominantly secrete IFN- $\gamma$ following ischemia, toxin-induced injury or stimulation in the presence of IL-18 plus IL-12, but these cells secrete IFN- $\gamma$, IL-4 and IL-17 in response to $\alpha \mathrm{GalCer}{ }^{33}$

Following activation, type I NKT cells can further stimulate DCs, NK cells, B cells, and conventional $\mathrm{CD}^{+}$and $\mathrm{CD}^{+}$ $\mathrm{T}$ cells that can further mediate liver damage. ${ }^{18,34}$ Furthermore, cytokines and chemokines secreted by activated type I NKT cells result in the recruitment of neutrophils, myeloid cells and monocytes to the liver. ${ }^{35-40}$ Type I NKT cells can promote fibrogenesis involving the Hedgehog pathway, ${ }^{41,42}$ and cytokines including osteopontin (OPN) lead to hepatic stellate cell (HSC) activation. ${ }^{14,39}$ In addition, activated type I NKT cells can also kill hepatocytes directly via Fas/FasL interactions or indirectly by activating $\mathrm{NK}$ cells. KCs are located at the interface of the portal vein (within the sinusoidal vascular space) and the systemic circulation, and this critical location makes these cells key factors in the activation of the immune response by recognizing danger signals (pathogenassociated molecular patterns and danger-associated molecular patterns) through the expression of TLR and nucleotidebinding oligomerization domain-like receptors. ${ }^{43}$ Activated KCs produce a variety of pro-inflammatory cytokines, such as IL-1 $\beta$, IL-18, tumor necrosis factor (TNF)- $\alpha$ and IL-12, which have important roles in regulating the recruitment and activation of type I NKT cells. ${ }^{44,45}$

\section{ANTIGEN RECOGNITION AND ACTIVATION OF TYPE II NKT CELLS}

Our laboratory has identified and characterized a major subset of type II NKT cells that is reactive to the self-glycolipid sulfatide., ${ }^{419,20,36}$ Some type II NKT cells have also been demonstrated to recognize other $\beta$-linked glycolipids, including $\beta$-D-glucopyranosylceramide, $\beta \mathrm{GluCer}$ and $\beta \mathrm{GalCer}$, as well as some pollen-derived lipids. ${ }^{21,46,47}$ More recently, we demonstrated that other self-phospholipids, including lysophosphatidylcholine (LPC), lysosphingomyelin and lyso-plateletactivating factor, can effectively stimulate a subset of type II NKT cells in a CD1d-dependent manner both in vitro and in vivo. ${ }^{48}$ IL-13-secreting LPC-reactive type II NKT cells have also been reported to be increased in myeloma patients relative to healthy donors. ${ }^{49}$ A subset of type II NKT cells can also be stimulated by the lysophosphatidylethanolamine, ${ }^{50}$ which is generated in hepatocytes following hepatitis $\mathrm{B}$ infection. ${ }^{51}$ Phospholipids, such as phosphatidylglycerol, phosphatidylinositol and cardiolipin, can also activate murine type II NKT cell hybridomas. ${ }^{52}$ Recently, murine and human type II NKT cells specific for glucosylsphingosine 1 have been found to be associated with disease severity in a murine model and also in peripheral blood mononuclear cells from Gaucher disease patients. ${ }^{53}$

In contrast to the predominantly pro-inflammatory role of type I NKT cells in liver damage, type II NKT cells are able to suppress the pro-inflammatory response induced by type I NKT cells and consequently protect against liver damage. Furthermore, the activation of type II NKT cells with sulfatide does not induce the activation of B, NK or T cells. ${ }^{54}$ Therefore, the study of type II NKT cells following sulfatide activation has 
uncovered a dominant immunoregulatory pathway that has been demonstrated to be involved in protection against hepatic ischemia reperfusion injury (IRI), ${ }^{35}$ type 1 diabetes ${ }^{55}$ and experimental autoimmune encephalomyelitis. ${ }^{20}$

\section{CROSS-REGULATION BETWEEN TYPE I AND TYPE II NKT CELLS}

A major mechanism of cross-regulation between type I and type II NKT cells is revealed following the activation of type II NKT cells by a self-glycolipid or lysophospholipid. Following the administration of sulfatide, CD1d is upregulated on plasmacytoid DCs, but not conventional DCs (cDCs), which results in the activation of sulfatide-reactive type II NKT cells and the secretion of IL-12 and macrophage inflammatory protein-2, which in turn leads to the recruitment of type I NKT cells into the liver. Interestingly, these cellular interactions lead to the tolerization of $\mathrm{cDCs}$ and anergy induction in the recruited type I NKT cells. ${ }^{36}$ Both anergic type I NKT cells and IL-10-secreting cDCs also inhibit adaptive immunity following sulfatide-mediated activation of type II NKT cells by suppressing the cytokine burst and neutrophil recruitment into the liver, which thereby attenuates concanavalin A-induced hepatitis, IRI and alcoholic liver disease (ALD). ${ }^{36,38}$ A similar mechanism of immune regulation by type II NKT cells has been found to be involved following their activation by LPC. ${ }^{48}$ Sulfatide-mediated activation of type II NKT cells can also modulate the activities of other immune cells, such as myeloidderived suppressor cells (MDSCs), CD11 $\mathrm{b}^{+} \mathrm{Gr}-1^{+}$cells, B cells and neutrophils. ${ }^{37,38,56}$ The opposing roles of type I and type II NKT cells have also been demonstrated in immune responses against parasites, antitumor immunity and autoimmunity (Figure 1). ${ }^{4,57-59}$

In contrast, there are experimental data that suggest that type I NKT cells could potentially cross-regulate type II NKT activity. ${ }^{59}$ It has been demonstrated that the sulfatide stimulation of type II NKT cells completely inhibits the protective effect of $\alpha$ GalCer in the 15-12RM fibrosarcoma model but does not completely abrogate the protection afforded by $\alpha \mathrm{GalCer}$ in CT26 colon cancer lung metastasis, and that type I NKT cells may exhibit moderate suppressive effects on the activity of type II NKT cells. A better understanding of the mechanisms involved in cross-regulation between type I and type II NKT cell subsets is crucial for the development of strategies to manipulate the outcome of the immune response in human inflammatory liver diseases.

More recently, type II NKT cell activation induced by IL-25 has been demonstrated to be involved in the regulation of inflammation in adipose tissue and the prevention of high fat diet-induced obesity in mice. The transfer of type II NKT cells into obese mice induces greater and more prolonged weight loss and improved glucose tolerance. ${ }^{60}$

Interestingly, similar to conventional $\mathrm{T}$ cells, type $\mathrm{I}$ NKT cells also become unresponsive or anergic after a secondary challenge following a primary TCR activation with $\alpha$ GalCer. Anergic type I NKT cells express greater levels of programmed death 1 (PD-1). Furthermore, blocking the
PD-1/PD ligand 1 (PD-L1) pathway prevents $\alpha$ GalCer-induced but not bacterial lipid- or sulfatide-induced anergy in type I NKT cells ${ }^{61,62}$ Recent studies have further indicated the involvement of the E3-ubiquitin ligase Cbl-b and mTOR signaling in anergy induction in type I NKT cells. ${ }^{63}$

\section{ROLES OF NKT CELL SUBSETS IN PATHOLOGICAL CONDITIONS IN THE LIVER}

In the majority of experimental models of chronic liver diseases, including those of $\mathrm{IRI}^{64}$ con A-induced hepatitis, ${ }^{36,54,65}$ primary biliary cirrhosis $(\mathrm{PBC})^{66}$ and nonalcoholic fatty liver disease (NAFLD), ${ }^{67-69}$ type I NKT cells have been demonstrated to have a pathogenic role. However, in acute liver injury models, type I NKT cells can have a protective role. For example, in a mouse model of biliary obstruction and cholestasis, and in a model of acute $\mathrm{CCl}_{4}$-induced fibrosis, type I NKT cell-dependent inhibition of macrophage inflammatory protein-2, KC and TNF $\alpha$ production leads to the inhibition of both neutrophil infiltration and liver injury. ${ }^{70-72}$ Collectively, these data suggest that while in acute injury, type I NKT cell activation may be protective, in chronic conditions, type I NKT cells promote liver injury. Consistent with the dual role of type I NKT cells, Wang et al..$^{73}$ reported that $\alpha$ GalCer-mediated activation of these cells promotes neutrophil infiltration and hepatitis in a STAT-6 dependent manner, whereas this activation can also control liver injury by inducing neutrophil apoptosis via a STAT-1-dependent mechanism.

\section{Alcoholic liver disease}

ALD is a common medical condition that results from chronic alcohol abuse and is among the most frequent causes of death in the general population. This disease can progress from hepatic steatosis (fatty liver) to alcoholic hepatitis (10-35\%) and ultimately to alcoholic fibrosis or cirrhosis (8-20\%). The cellular and molecular mechanisms underlying ALD involve complex interactions between innate immune cells (NK, NKT and $\gamma \delta \mathrm{T}$ cells), parenchymal cells (hepatocytes) and nonparenchymal cells (sinusoidal endothelial cells, KCs, HSCs and DCs). ${ }^{74}$ Activation of KCs via LPS/TLR signaling-dependent mechanisms following alcohol consumption results in increased secretion of a variety of pro-inflammatory cytokines and chemokines in addition to eicosanoids and reactive oxygen species. ${ }^{75,76}$ Indeed, TNF $\alpha$ and IL-1 $\beta$ levels are increased in the sera and livers of alcohol-fed mice, and the neutralization of IL-1 $\beta$ in KC attenuates type I NKT cell accumulation and steatosis. Moreover, Cui et al. ${ }^{44}$ demonstrated that KC-derived NLRP3 inflammasome activation and IL-1 $\beta$ release are essential for hepatic NKT cell accumulation and activation in ALD. Consistently, gut-derived bacteria or their products, such as lipopolysaccharides, that are leaked into the circulation activate KCs via nucleotide-binding oligomerization domain-like receptors, specifically NLRP3, which could lead to NKT cell activation. $^{44}$

Using a murine model of chronic plus binge ethanol feeding with a Lieber-DeCarli liquid diet, we recently demonstrated that an increased number of activated type I, but not type II 


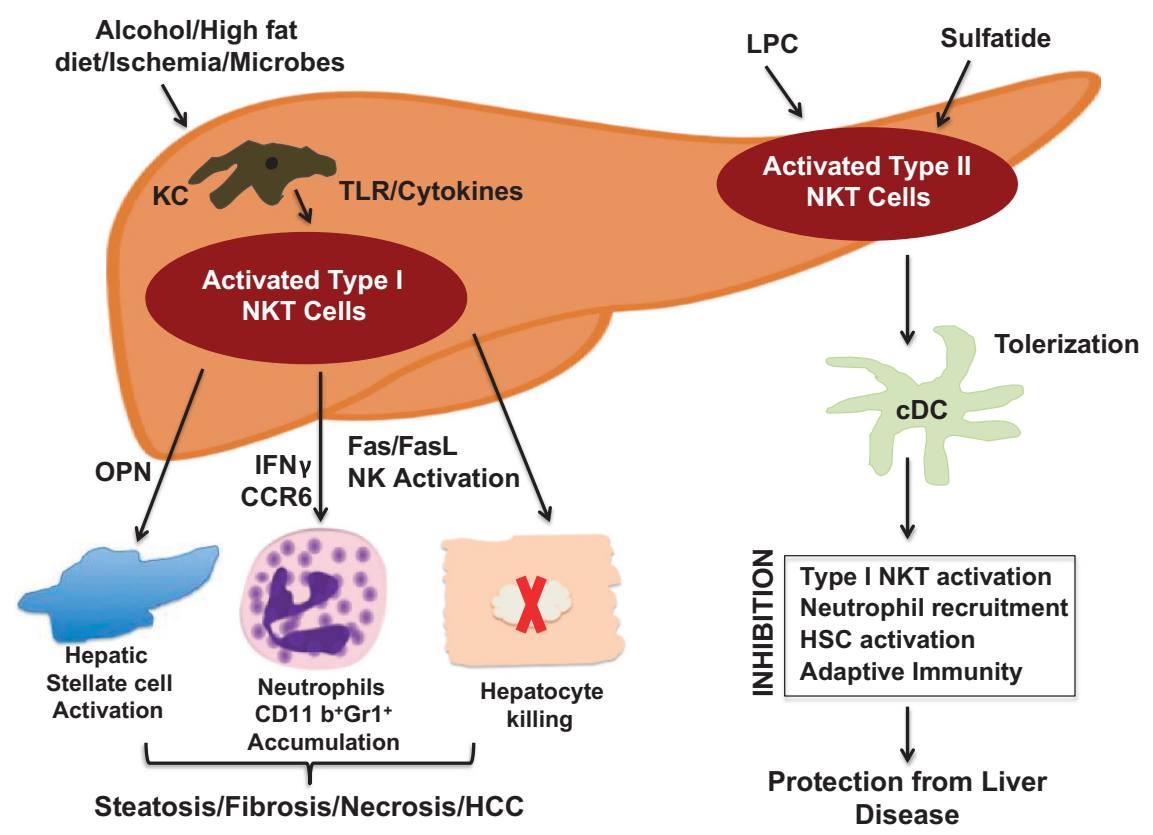

Figure 1 A proposed model depicting the opposing roles of type I and type II NKT cells in inflammatory diseases in the liver. Type I NKT cells are rapidly activated following liver injuries induced by alcohol, high-fat diet, ischemia and/or gut-derived microbial products. Liver-resident antigen-presenting cells, such as KCs, and TLRs/cytokines mediate their activation, which results in the cytokine/chemokinedependent recruitment of myeloid cells $(\mathrm{CD} 11 \mathrm{~b}+\mathrm{Gr}-1+)$ and neutrophils, and the activation of HSC and NK cells. These cellular interactions lead to steatosis, fibrosis and hepatocyte necrosis. These events are also involved in the development of HCC. In contrast, type II NKT cells are activated following the presentation of self-lipids, such as sulfatide and LPC, which results in the induction of a crossregulatory pathway that inhibits type I NKT cells, tolerizes cDCs and blocks the inflammatory cascade and liver disease. cDCs, conventional DCs; HCC, hepatocellular carcinoma; HSC, hepatic stellate cell; KC, Kupffer cell; LPC, Iysophosphatidylcholine; NK, natural killer; NKT, natural killer T cells; OPN, osteopontin; TLR, toll-like receptor.

NKT, cells accumulate in the liver, which is consistent with another model of mice that are fed alcohol via an intragastric tube. ${ }^{38,40,77,78}$ Moreover, J $\alpha 18^{-/-}$mice (which are deficient in type I NKT cells) and CD1d ${ }^{-1-}$ mice (which are deficient in both NKT cell subsets) are protected against liver injury after alcohol intake. ${ }^{38,40}$ The activation of type I NKT cells is required for the hepatic recruitment of inflammatory Gr-1 ${ }^{+} \mathrm{CD} 11 \mathrm{~b}^{+}$cells and neutrophils that results in liver tissue damage. Accordingly, several cytokines and chemokines that are associated with inflammation and neutrophil recruitment, including OPN, IL-1 $\beta$, IL-6, TNF $\alpha$, macrophage inflammatory protein-2, MIP-1 $\beta$ and CXCR1, are upregulated in the livers of alcohol-fed wild-type mice but not in type I NKT cell-deficient mice. Furthermore, the inhibition of type I NKT cells via a direct pathway involving all-trans retinoic acid or the indirect mechanisms of sulfatide-mediated activation of type II NKT cells or the administration of an anti-CD1d blocking antibody significantly suppresses this pro-inflammatory cascade and ameliorates ALD. ${ }^{38,40}$ Importantly, the RAR $\gamma$-signaling pathway is involved in the inhibition of type I NKT cells by ATRA owing to the greater expression of RAR $\gamma$ in these cells; accordingly, the clinically relevant $\operatorname{RAR} \gamma$ agonist tazarotene blocks the development of ALD. ${ }^{38}$

In humans, the role of type I NKT cells in ALD has not been carefully investigated. However, consistent with the data from murine models, pro-inflammatory cytokines, including TNF $\alpha$,
IL-6, IL-8, OPN and IL-1, are increased in the sera and liver biopsies of humans with alcoholic hepatitis and may be correlated with disease severity/mortality. ${ }^{13}$ Furthermore, E-selectin expression is highly upregulated in human alcoholic fatty livers but not in alcoholic cirrhosis, which suggests that E-selectin may have a role in hepatic neutrophil infiltration and injury in the early stages of disease. ${ }^{77}$ Moreover, in patients with alcohol hepatitis, reduced NKG2D expression in CTLs, NK cells and type I NKT cells has been found to correlate with disease severity, which suggests that these cells are involved in promoting liver damage. ${ }^{79}$ In contrast, increased frequencies of IL-22-producing cells and increased IL-17 plasma levels are associated with improved prognoses in patients with alcoholic hepatitis. ${ }^{79-81}$

\section{Nonalcoholic fatty liver disease}

NAFLD is the most frequent chronic liver disease. NAFLD affects $10-20 \%$ of the population in developed countries, and its prevalence is increasing with the rise of diabetes and obesity. NAFLD is defined by the abnormal accumulation of fat within the liver, or steatosis, which can progress to severe inflammatory cell infiltration or nonalcoholic steatohepatitis (NASH) accompanied by fibrosis or necrosis or progress to liver cirrhosis and hepatocellular carcinoma (HCC). ${ }^{82,83}$ Although a detailed CD1d tetramer-based analysis of the activation profiles of NKT cell subsets in NASH is lacking, reduced 
numbers of type I NKT cells are found in mice fed methionine/ choline-deficient or high-fat diets (CD-HFDs) and in ob/ob mice. ${ }^{67,84}$ Activation of $\mathrm{KC}$ or the Tim-3/Gal-9 signaling pathway can lead to apoptosis in type I NKT cells in the liver, and could thus contribute to steatosis and insulin resistance. ${ }^{45,67,85}$ Indeed, the depletion of KCs via treatment with gadolinium chloride reduces hepatic IL-12 expression and does not lead to type I NKT apoptosis, and thereby prevents diet-induced hepatic steatosis and insulin resistance. Consistently, the activation of the Hedgehog pathway and HSCs has been revealed to be associated with type I NKT cells in mice fed an MCD diet or a combination of a CD-HFD. ${ }^{68,69,86}$ Similarly, the hepatic CD1d expression and increased numbers of $\mathrm{CD}^{+}$ $\mathrm{CD}^{2} 6^{+}$cells in NASH patients suggest a potentially important role of NKT cells in this disease. ${ }^{68,69,86,87}$

\section{Autoimmune hepatitis}

$\mathrm{AIH}$ is a chronic autoimmune inflammation of the liver that is characterized by T-cell periportal and intralobular infiltration of the liver in the absence of other liver diseases and in association with increased serum transaminases, hypergammaglobulinemia and hepatocyte-specific autoantibodies. AIH is strongly linked to HLA-A1, -B8, -DR3 and -DRB1. There are at least two subtypes of $\mathrm{AIH}$; type I is characterized by autoantibodies directed against smooth muscle antigens and antinuclear antibodies, and type II is characterized by autoantibodies directed against cytochrome p450 2D6 or formiminotransferase cyclodeaminase. Both types also share autoantibodies that recognize O-phosphoseryl-tRNA (Sec) selenium transferase/soluble liver antigen. ${ }^{88-90}$ Earlier studies revealed that while type I NKT cells are pathogenic, type II NKT activation protects mice against ConA-induced hepatitis. ${ }^{36,65}$ Recently, a strong correlation of high levels of IL-17 in the serum and liver with disease severity was found in patients with $\mathrm{PBC}$ and $\mathrm{AIH}$, which suggests a role of IL17-producing type I NKT cells. ${ }^{91,92}$ Consistently, significant increases in the frequencies of IL-17+ expressing cells have been demonstrated in the portal areas of liver biopsies from $\mathrm{PBC}$, chronic hepatitis $\mathrm{C}(\mathrm{HCV}), \mathrm{NASH}$ and $\mathrm{AIH}$ patients compared with control subjects. ${ }^{88}$ In a murine model of $\alpha$ GalCer-induced liver injury, CD4+ type I NKT cells have been found to be the main source of IL-17, and accordingly, administration of anti-IL-17-neutralizing monoclonal antibodies before $\alpha \mathrm{GalCer}$ injection significantly exacerbates hepatitis, the hepatic recruitment of neutrophils, and the production of IL-12 and TNF $\alpha$ by pro-inflammatory monocytes. In contrast, the administration of exogenous recombinant murine IL-17 before $\alpha \mathrm{GalCer}$ injection attenuates hepatitis and prevents the recruitment of inflammatory monocytes to the liver. Thus, secretion of IL-17 by type I NKT cells could have a crucial role in $\mathrm{AIH} .{ }^{93}$

\section{$\mathrm{PBC}$ and primary sclerosing cholangitis}

Biliary diseases such as primary sclerosing cholangitis (PSC) and $\mathrm{PBC}$ are characterized by an inflammatory immune response that leads to the destruction of the bile ducts.
Cholangiocytes have been suggested to have an active role in immune responses. ${ }^{94,95}$ Notably, murine and human cholangiocytes express $\mathrm{CD} 1 \mathrm{~d}$ and can present exogenous and endogenous lipid antigens to both type I and type II NKT cells. ${ }^{66}$ Hepatic CD1d expression and type I NKT cell numbers have consistently been found to be elevated in patients with PBC 95. However, CD1d expression is downregulated in the biliary epithelia of patients with late PSC and PBC. Consistent with the pathogenic role of type I NKT cells in other liver diseases, an important role for type I NKT cells in the initiation of PBC was recently demonstrated in two murine models. In these models, NKT deficiency was found to attenuate the development of PBC induced by the overexpression of a dominant-negative TGF- $\beta R$ in $\mathrm{T}$ cells or by infection with novosphingobium aromaticivorans. It is becoming clear that type I NKT cells cross talk with other autoreactive intrahepatic $\mathrm{B}$ cells and conventional CD4/CD8 T cells that are involved in these autoimmune diseases. ${ }^{90,96,97}$

\section{Chronic hepatitis B and HCV infection}

Chronic hepatitis B (HBV) and HCV infections account for $57 \%$ of the cases of liver cirrhosis and $78 \%$ of the cases of primary liver cancer worldwide, and cause one million deaths per year. Type I NKT cells may have a role in controlling HCV infections, particularly in the early stages of HCV infection in humans. Via IFN- $\gamma$ secretion, type I NKT cells have been demonstrated to be capable of inhibiting HCV replication in hepatocytes, ${ }^{98}$ and their activities are positively correlated with the outcome of acute HCV infection and the efficacy of IFN- $\alpha$ treatment in chronic HCV infection. Numerous studies have reported that type I NKT cells are significantly depleted during chronic $\mathrm{HCV}$ infection, which likely contributes to the failure of its resolution. Similarly high numbers of activated type I NKT cells have been found in the early stages of HBV infection in humans. ${ }^{99-101}$ The inhibitory effect of type I NKT cells on HBV infection is likely mediated via the secretion of IFN- $\gamma$, which inhibits HBV replication and stimulates adaptive immune responses. ${ }^{97}$ Although NKT cells can control HBV and HCV replication in the early stages of infection, NKT cells may also contribute to liver injury during chronic viral hepatitis infection via several mechanisms, including the lysis of hepatocytes, the production of pro-inflammatory cytokines, the induction of hepatocyte apoptosis, and the inhibition of hepatocyte proliferation. ${ }^{102-104}$

\section{Hepatocellular carcinoma}

HCC is frequently associated with chronic inflammatory liver diseases such as NASH and viral hepatitis. ${ }^{105}$ Generally, NKT cells have a crucial dual role in cancer: they can promote an antitumor response via the activation of effector CD4/CD8+ $\mathrm{T}$ cells; and they can also promote tumor growth by recruiting suppressor or regulatory $\mathrm{T}$ cells to induce tolerance or by producing Th2 cytokines, which subsequently result in the inhibition of tumor antigen-specific CD8+ T-cell expansion. ${ }^{106}$ Although NKT cells are abundant in the liver, relatively fewer studies have attempted to clarify their role in HCC. 
It has been shown that long-term feeding with a CD-HFD induces the activation of intrahepatic CD8+ $\mathrm{T}$ cells and NKT cells, as well as the secretion of inflammatory cytokines in mice. NKT cells primarily cause steatosis via the secretion of LIGHT, whereas CD8+ and NKT cells cooperatively induce liver damage. Hepatocellular TLR4 and canonical nuclear factor- $\kappa \mathrm{B}$ signaling facilitate the NASH-to-HCC transition, which suggests the involvement of distinct molecular mechanisms in NASH and HCC development. CD4 ${ }^{+}$type I NKT cells can also mediate antitumor effects through the inhibition of the inflammatory response triggered by the activation of the oncogenic $\beta$-catenin pathway. ${ }^{107}$ In addition, NKT cells suppress tumor growth in mice after adoptive transfer of HCC tumor lines. ${ }^{50,108}$ In patients with HCC, there is an increase in the frequency of NKT in the tumor relative to the blood, and CD4+ V $\alpha 24 / \mathrm{V} \beta 11$ type I NKT cells secreting Th2 cytokines accumulate in human intrahepatic malignant tumors and inhibit tumor-specific CD8+ T-cell responses. ${ }^{105}$

\section{Liver injury induced by toxins and drugs}

The liver is specialized to metabolize circulating drugs or toxins, but the metabolism of these drugs frequently induces liver injury. ${ }^{109}$ The pathological role of NKT cells in druginduced liver injury has been investigated using the murine model of acetaminophen-induced liver injury. Type I NKTdeficient mice have been found to be more susceptible to acetaminophen-induced liver injury than wild-type mice. ${ }^{110}$ Similarly, chronic $\mathrm{CCl}_{4^{-}}$, Con A- and paracetamol-induced liver injuries are blunted in type I NKT-deficient mice. ${ }^{38,71}$ The drug or its metabolites trigger the activation of type I NKT cells that are responsible for the massive release of high levels of cytokines, including OPN, IFN- $\alpha$ and IL- 4 , and the increased expression of FasL by hepatocytes, which leads to massive hepatocellular necrosis. ${ }^{4,14,39,109}$

\section{Ischemia and reperfusion injury and liver transplantation} IRI represents a complex inflammatory immune response that generally occurs in a sterile environment and results in tissue damage. ${ }^{111}$ IRI is a major problem in liver resection and liver transplantation. IRI involves the activation of both innate and adaptive immunity that leads to the necrotic cell death of hepatocytes. The sterile immune response also involves signaling through pattern recognition receptors such as TCRs, for example, TLR4. ${ }^{112}$ TLR4 likely mediates the early activation of type I NKT cells that secrete IFN- $\gamma$ during liver IRI as demonstrated recently. ${ }^{35}$ Accordingly, mice that are deficient in type I NKT cells or the cross-regulation of type I NKT cells following sulfatide-mediated activation of type II NKT cells leads to significantly reduced inflammatory infiltrate, including $\mathrm{CD} 11 \mathrm{~b}+\mathrm{Gr}-1+$ cells, and liver damage following reperfusion. ${ }^{35}$ The tolerization of cDCs following the activation of type II NKT cells has a major role in the control of IRI because the depletion of cDCs leads to an increase in hepatic injury. ${ }^{113}$ Consistent with the idea that NKT cells can control the accumulation of granulocytes and neutrophils in tissues, their excessive accumulation can promote uncontrolled inflammation and tissue damage during IRI. ${ }^{114,115}$ It is also relevant to mention that because adaptive immune responses also become involved in IRI, the tolerization of DCs following the cross-regulation of NKT cells should be able to blunt the further detrimental effects of both conventional CD4+ and CD8+ T cells.

In liver transplantation, both the host-residual and donorderived NKT cells exert protective functions that are particularly well described in graft-versus-host disease. Whereas the type I NKT subset is involved in protection mediated by hostresidual T cells, type II NKT cells have critical roles in donorderived protective effects. ${ }^{116,117}$ Indeed, on the one hand, the adoptive transfer of type I NKT cells or the administration of $\alpha \mathrm{GalCer}$ can attenuate graft-versus-host disease in recipient mice due to the vigorous secretion of IL- 4 by type I NKT cells and the subsequent Th2 polarization of the immune response. On the other hand, donor type II NKT cells not only produce IL-4-like type I NKT cells but also produce IFN- $\gamma$, which induces apoptosis in donor $\mathrm{CD}^{+}$and $\mathrm{CD} 8^{+}$ $\mathrm{T}$ cells in a Fas-dependent manner. ${ }^{118}$ Moreover, human CD $161^{+}$CD1d-reactive BM-derived type II NKT cells have been found to specifically suppress the mixed lymphocyte reaction and are able to induce tolerance to allografts. ${ }^{119}$ Collectively, the appropriate targeting of the NKT cell subsets may have an important role in the development of strategies for reducing tissue damage due to IRI and liver transplantation.

\section{Liver regeneration}

The liver has a substantial ability to regenerate following tissue loss or injury. This regeneration process is controlled by various cytokines, growth factors and hormones. ${ }^{120-122}$ The accumulation of type I NKT cells in the liver following partial hepatectomy suggests that type I NKT cells may have a role in liver regeneration. Accordingly, under inflammatory conditions (for example, partial hepatectomy in HBV transgenic mice), the depletion of NKT cells significantly enhances liver regeneration..$^{98,102}$ More recently, Yin et al. ${ }^{123}$ also revealed that the activation of type I NKT cells with $\alpha$ GalCer strongly inhibits liver regeneration via a mechanism that depends on NKT-derived IFN- $\gamma$ and IL-4 secretion. Similarly, the reduction of the commensal bacterial load after oral ampicillin treatment induces the expansion of IL-12-secreting KCs that overactivate hepatic type I NKT cells to produce higher IFN- $\gamma$ levels that inhibit liver regeneration. ${ }^{124}$ Collectively, the activation of type I NKT cells in inflammatory conditions appears to inhibit liver regeneration.

\section{FUTURE PERSPECTIVE}

We have discussed many of the key aspects of NKT cell activation and their functions in inflammatory conditions. Most of the advances in the understanding of the roles of NKT cell subsets in the liver have come from studies with animal models. Experimental and clinical studies are complicated by the fact that there are at least two major subsets of CD1d-restricted NKT cells that have opposing functions and 
can be differentially activated at different time points during the progression of the disease. Different degrees of NKT cell activation can also lead to the secretion of a wide array of cytokines, chemokines and other factors. Furthermore, because NKT cells also modulate the activity of other key immune cells, including KCs, macrophages, DCs and major histocompatibility complex-restricted CD4+/CD8+ cells, a molecular understanding of these cross-regulatory influences will be key for understanding how the liver is able to maintain a proper balance between immune tolerance and immunity. During chronic liver disease processes, the actions of the different NKT cell subsets are inextricably interconnected and change depending on the stage of the disease. It will be important to develop specific reliable reagents to identify and characterize both type I and type II NKT cell subsets in humans, and also to carefully use CD1d tetramers and other reagents that can differentiate their activation in peripheral blood mononuclear cells and liver tissues.

\section{CONFLICT OF INTEREST}

The authors declare no conflict of interest.

\section{ACKNOWLEDGEMENTS}

This work was supported by grants from the National Institutes of Health, USA, R01 CA100660 and R01 AA020864 (to VK). We thank the other members of the Kumar laboratory and Dr Randle Ware for a critical reading of the manuscript.

1 Luedde T, Schwabe RF. NF-kappaB in the liver-linking injury, fibrosis and hepatocellular carcinoma. Nat Rev Gastroenterol Hepatol 2011; 8: $108-118$

2 Crispe IN. Hepatic T cells and liver tolerance. Nat Rev Immunol 2003; 3: 51-62.

3 Herkel J, Schuchmann M, Tiegs G, Lohse AW. Immune-mediated liver injury. J Hepatol 2005; 42: 920-923.

4 Arrenberg P, Halder R, Kumar V. Cross-regulation between distinct natural killer T cell subsets influences immune response to self and foreign antigens. J Cell Physiol 2009; 218: 246-250.

5 Kumar V, Delovitch TL. Different subsets of natural killer T cells may vary in their roles in health and disease. Immunology 2014; 142: 321-336.

6 Rhost S, Sedimbi S, Kadri N, Cardell SL. Immunomodulatory type II natural killer T lymphocytes in health and disease. Scand J Immunol 2012; 76: 246-255.

7 Taniguchi M, Seino K, Nakayama T. The NKT cell system: bridging innate and acquired immunity. Nat Immunol 2003; 4: 1164-1165.

8 Bendelac A, Savage PB, Teyton L. The biology of NKT cells. Annu Rev Immunol 2007; 25: 297-336.

9 Godfrey DI, Stankovic S, Baxter AG. Raising the NKT cell family. Nat Immunol 2010; 11: 197-206.

10 Brigl M, Brenner MB. CD1: antigen presentation and T cell function. Annu Rev Immunol 2004: 22: 817-890.

11 Geissmann F, Cameron TO, Sidobre S, Manlongat N, Kronenberg M, Briskin MJ et al. Intravascular immune surveillance by CXCR6+ NKT cells patrolling liver sinusoids. PLoS Biol 2005; 3: e113.

12 Lee WY, Moriarty TJ, Wong CH, Zhou H, Strieter RM, van Rooijen $\mathrm{N}$ et al. An intravascular immune response to Borrelia burgdorferi involves Kupffer cells and iNKT cells. Nat Immunol 2010; 11: 295-302.

13 Gao B, Bataller R. Alcoholic liver disease: pathogenesis and new therapeutic targets. Gastroenterology 2011; 141: 1572-1585.
14 Kumar V. NKT cell subsets: promoters and protectors in inflammatory liver disease. J Hepatol 2013; 59: 618-620.

15 Benlagha $K$, Weiss A, Beavis A, Teyton L, Bendelac A. In vivo identification of glycolipid antigen-specific $T$ cells using fluorescent CD1d tetramers. J Exp Med 2000; 191: 1895-1903.

16 Jahng AW, Maricic I, Pedersen B, Burdin N, Naidenko O, Kronenberg $\mathrm{M}$ et al. Activation of natural killer $\mathrm{T}$ cells potentiates or prevents experimental autoimmune encephalomyelitis. J Exp Med 2001; 194: 1789-1799.

17 Matsuda JL, Naidenko OV, Gapin L, Nakayama T, Taniguchi M, Wang CR et al. Tracking the response of natural killer T cells to a glycolipid antigen using CD1d tetramers. J Exp Med 2000; 192: 741-754.

18 Bendelac A, Rivera MN, Park SH, Roark JH. Mouse CD1-specific NK1 T cells: development, specificity, and function. Annu Rev Immunol 1997; 15: 535-562.

19 Arrenberg P, Halder R, Dai Y, Maricic I, Kumar V. Oligoclonality and innate-like features in the TCR repertoire of type II NKT cells reactive to a beta-linked self-glycolipid. Proc Natl Acad Sci USA 2010; 107: 10984-10989.

20 Jahng A, Maricic I, Aguilera C, Cardell S, Halder RC, Kumar V. Prevention of autoimmunity by targeting a distinct, noninvariant CD1d-reactive T cell population reactive to sulfatide. J Exp Med 2004: 199: 947-957.

21 Girardi E, Maricic I, Wang J, Mac TT, Iyer P, Kumar V et al. Type II natural killer $T$ cells use features of both innate-like and conventional T cells to recognize sulfatide self antigens. Nat Immunol 2012; 13: 851-856.

22 Patel O, Pellicci DG, Gras S, Sandoval-Romero ML, Uldrich AP, Mallevaey $\mathrm{T}$ et al. Recognition of CD1d-sulfatide mediated by a type II natural killer T cell antigen receptor. Nat Immunol 2012; 13: 857-863.

23 Lopez-Sagaseta J, Sibener LV, Kung JE, Gumperz J, Adams EJ. Lysophospholipid presentation by $\mathrm{CD} 1 \mathrm{~d}$ and recognition by a human Natural Killer T-cell receptor. EMBO J 2012; 31: 2047-2059.

24 Pellicci DG, Patel O, Kjer-Nielsen L, Pang SS, Sullivan LC, Kyparissoudis $\mathrm{K}$ et al. Differential recognition of $\mathrm{CD} 1 \mathrm{~d}$-alphagalactosyl ceramide by the $\mathrm{V}$ beta 8.2 and $\mathrm{V}$ beta 7 semi-invariant NKT T cell receptors. Immunity 2009; 31: 47-59.

25 Zhou D, Cantu C 3rd, Sagiv Y, Schrantz N, Kulkarni AB, Qi X et al. Editing of CD1d-bound lipid antigens by endosomal lipid transfer proteins. Science 2004; 303: 523-527.

26 Kinjo Y, Wu D, Kim G, Xing GW, Poles MA, Ho DD et al. Recognition of bacterial glycosphingolipids by natural killer T cells. Nature 2005; 434: 520-525.

27 Pei B, Speak AO, Shepherd D, Butters T, Cerundolo V, Platt FM et al. Diverse endogenous antigens for mouse NKT cells: selfantigens that are not glycosphingolipids. J Immunol 2011; 186: 1348-1360.

28 Rossjohn J, Pellicci DG, Patel O, Gapin L, Godfrey DI. Recognition of CD1d-restricted antigens by natural killer T cells. Nat Rev Immunol 2012; 12: 845-857.

29 Gapin L, Godfrey DI, Rossjohn J. Natural Killer T cell obsession with self-antigens. Curr Opin Immunol 2013; 25: 168-173.

30 Kinjo $\mathrm{Y}$, Kitano N, Kronenberg M. The role of invariant natural killer $\mathrm{T}$ cells in microbial immunity. J Infect Chemother 2013; 19: 560-570.

31 Kronenberg M, Rudensky A. Regulation of immunity by self-reactive T cells. Nature 2005; 435: 598-604.

32 Novak J, Beaudoin L, Park S, Griseri T, Teyton L, Bendelac A et al. Prevention of type 1 diabetes by invariant NKT cells is independent of peripheral CD1d expression. J Immunol 2007; 178: 1332-1340.

33 Brigl M, Brenner MB. How invariant natural killer T cells respond to infection by recognizing microbial or endogenous lipid antigens. Semin Immunol 2010; 22: 79-86.

34 Godfrey DI, Kronenberg M. Going both ways: immune regulation via CD1d-dependent NKT cells. J Clin Invest 2004; 114: 1379-1388.

35 Arrenberg P, Maricic I, Kumar V. Sulfatide-mediated activation of type II natural killer $T$ cells prevents hepatic ischemic reperfusion injury in mice. Gastroenterology 2011; 140: 646-655.

36 Halder RC, Aguilera C, Maricic I, Kumar V. Type II NKT cell-mediated anergy induction in type I NKT cells prevents inflammatory liver disease. J Clin Invest 2007; 117: 2302-2312. 
37 Maricic I, Girardi E, Zajonc DM, Kumar V. Recognition of lysophosphatidylcholine by type II NKT cells and protection from an inflammatory liver disease. J Immunol 2014; 193: 4580-4589.

38 Maricic I, Sheng H, Marrero I, Seki E, Kisseleva T, Chaturvedi S et al. Inhibition of type I natural killer $\mathrm{T}$ cells by retinoids or following sulfatide-mediated activation of type II natural killer T cells attenuates alcoholic liver disease in mice. Hepatology 2015; 61: 1357-1369.

39 Marrero I, Ware R, Kumar V, Type NKT II. Cells in inflammation, autoimmunity, microbial immunity, and cancer. Front Immunol 2015; 6: 316 .

40 Mathews S, Feng D, Maricic I, Ju C, Kumar V, Gao B. Invariant natural killer $T$ cells contribute to chronic-plus-binge ethanolmediated liver injury by promoting hepatic neutrophil infiltration. Cell Mol Immunol 2016; 13: 206-216.

41 Nimmerjahn A, Kirchhoff F, Helmchen F. Resting microglial cells are highly dynamic surveillants of brain parenchyma in vivo. Science 2005; 308: 1314-1318.

42 Kumar V, Stellrecht K, Sercarz E. Inactivation of $T$ cell receptor peptide-specific CD4 regulatory $T$ cells induces chronic experimental autoimmune encephalomyelitis (EAE). J Exp Med 1996; 184: 1609-1617.

43 Barton GM, Kagan JC. A cell biological view of Toll-like receptor function: regulation through compartmentalization. Nat Rev Immunol 2009; 9: 535-542.

44 Cui K, Yan G, Xu C, Chen Y, Wang J, Zhou R et al. Invariant NKT cells promote alcohol-induced steatohepatitis through interleukin-1beta in mice. J Hepatol 2015; 62: 1311-1318.

45 Kremer M, Thomas E, Milton RJ, Perry AW, van Rooijen N, Wheeler MD et al. Kupffer cell and interleukin-12-dependent loss of natural killer T cells in hepatosteatosis. Hepatology 2010; 51: 130-141.

46 Rhost S, Lofbom L, Rynmark BM, Pei B, Mansson JE, Teneberg $\mathrm{S}$ et al. Identification of novel glycolipid ligands activating a sulfatide-reactive, CD1d-restricted, type II natural killer T Iymphocyte. Eur J Immunol 2012; 42: 2851-2860.

47 Roy KC, Maricic I, Khurana A, Smith TR, Halder RC, Kumar V. Involvement of secretory and endosomal compartments in presentation of an exogenous self-glycolipid to type II NKT cells. J Immunol 2008; 180: 2942-2950.

48 Maricic I, Halder R, Bischof F, Kumar V. Dendritic cells and anergic type I NKT cells play a crucial role in sulfatide-mediated immune regulation in experimental autoimmune encephalomyelitis. J Immunol 2014; 193: 1035-1046.

49 Chang DH, Deng H, Matthews P, Krasovsky J, Ragupathi G, Spisek R et al. Inflammation-associated lysophospholipids as ligands for CD1d-restricted T cells in human cancer. Blood 2008; 112: 1308-1316.

50 Shibolet O, Alper R, Zlotogarov L, Thalenfeld B, Engelhardt D, Rabbani $\mathrm{E}$ et al. NKT and CD8 lymphocytes mediate suppression of hepatocellular carcinoma growth via tumor antigen-pulsed dendritic cells. Int J Cancer 2003; 106: 236-243.

51 Zeissig S, Murata K, Sweet L, Publicover J, Hu Z, Kaser A et al. Hepatitis B virus-induced lipid alterations contribute to natural killer T cell-dependent protective immunity. Nat Med 2012; 18 : 1060-1068.

52 Tatituri RV, Watts GF, Bhowruth V, Barton N, Rothchild A, Hsu FF et al. Recognition of microbial and mammalian phospholipid antigens by NKT cells with diverse TCRs. Proc Natl Acad Sci USA 2013; 110: 1827-1832.

53 Nair S, Boddupalli CS, Verma R, Liu J, Yang R, Pastores GM et al. Type II NKT-TFH cells against Gaucher lipids regulate B-cell immunity and inflammation. Blood 2015; 125: 1256-1271.

54 Halder RC, Jahng A, Maricic I, Kumar V. Mini review: immune response to myelin-derived sulfatide and CNS-demyelination. Neurochem Res 2007; 32: 257-262.

55 Subramanian L, Blumenfeld H, Tohn R, Ly D, Aguilera C, Maricic I et al. NKT cells stimulated by long fatty acyl chain sulfatides significantly reduces the incidence of type 1 diabetes in nonobese diabetic mice. PLoS One 2012; 7: e37771.

56 Parekh VV, Wu L, Olivares-Villagomez D, Wilson KT, Van Kaer L. Activated invariant NKT cells control central nervous system autoimmunity in a mechanism that involves myeloid-derived suppressor cells. J Immunol 2013; 190: 1948-1960.

57 Duthie MS, Kahn M, White M, Kapur RP, Kahn SJ. Critical proinflammatory and anti-inflammatory functions of different subsets of CD1d-restricted natural killer T cells during Trypanosoma cruzi infection. Infect Immun 2005; 73: 181-192.

58 Mallevaey T, Zanetta JP, Faveeuw C, Fontaine J, Maes E, Platt $F$ et al. Activation of invariant NKT cells by the helminth parasite schistosoma mansoni. J Immunol 2006; 176: 2476-2485.

59 Terabe M, Berzofsky JA. NKT cells in immunoregulation of tumor immunity: a new immunoregulatory axis. Trends Immunol 2007; 28 : 491-496.

60 Hams E, Locksley RM, McKenzie AN, Fallon PG. Cutting edge: IL-25 elicits innate lymphoid type 2 and type II NKT cells that regulate obesity in mice. J Immunol 2013; 191: 5349-5353.

61 Parekh VV, Lalani S, Kim S, Halder R, Azuma M, Yagita H et al. PD-1/PD-2 blockade prevents anergy induction and enhances the anti-tumor activities of glycolipid-activated invariant NKT cells. J Immunol 2009; 182: 2816-2826.

62 Chang SW, Kim JY, Kim YJ, Kim YS, Lee JM, Azuma M et al. Programmed death-1/programmed death ligand 1 interaction regulates the induction and maintenance of invariant NKT cell anergy. J Immunol 2008; 181: 6707-6710.

63 Wu J, Shin J, Xie D, Wan GH, Gao B, Zhang XP. Tuberous sclerosis 1 promotes invariant NKT cell anergy and inhibits invariant NKT cell-mediated anti tumor immunity. J Immunol 2014; 192: 2643-2650.

64 Wallace KL, Marshall MA, Ramos SI, Lannigan JA, Field JJ, Strieter RM et al. NKT cells mediate pulmonary inflammation and dysfunction in murine sickle cell disease through production of IFN-gamma and CXCR3 chemokines. Blood 2009; 114: 667-676.

65 Takeda K, Hayakawa Y, Van Kaer L, Matsuda H, Yagita H, Okumura K. Critical contribution of liver natural killer T cells to a murine model of hepatitis. Proc Natl Acad Sci USA 2000; 97: 5498-5503.

66 Schrumpf E, Tan C, Karlsen TH, Sponheim J, Bjorkstrom NK, Sundnes $\mathrm{O}$ et al. The biliary epithelium presents antigens to and activates natural killer T cells. Hepatology 2015; 62: 1249-1259.

$67 \mathrm{Li} \mathrm{Z,} \mathrm{Soloski} \mathrm{MJ,} \mathrm{Diehl} \mathrm{AM.} \mathrm{Dietary} \mathrm{factors} \mathrm{alter} \mathrm{hepatic} \mathrm{innate}$ immune system in mice with nonalcoholic fatty liver disease. Hepatology 2005; 42: 880-885.

68 Syn WK, Agboola KM, Swiderska M, Michelotti GA, Liaskou E, Pang $\mathrm{H}$ et al. NKT-associated hedgehog and osteopontin drive fibrogenesis in non-alcoholic fatty liver disease. Gut 2012; 61: 1323-1329.

69 Syn WK, Oo YH, Pereira TA, Karaca GF, Jung Y, Omenetti A et al. Accumulation of natural killer T cells in progressive nonalcoholic fatty liver disease. Hepatology 2010; 51: 1998-2007.

70 Duwaerts CC, Sun EP, Cheng CW, van Rooijen N, Gregory SH. Cross-activating invariant NKT cells and kupffer cells suppress cholestatic liver injury in a mouse model of biliary obstruction. PLOS One 2013; 8: e79702.

71 Park O, Jeong WI, Wang L, Wang H, Lian ZX, Gershwin ME et al. Diverse roles of invariant natural killer T cells in liver injury and fibrosis induced by carbon tetrachloride. Hepatology 2009; 49: 1683-1694.

72 Wintermeyer P, Cheng CW, Gehring S, Hoffman BL, Holub M, Brossay $L$ et al. Invariant natural killer $T$ cells suppress the neutrophil inflammatory response in a mouse model of cholestatic liver damage. Gastroenterology 2009; 136: 1048-1059.

73 Wang H, Feng D, Park O, Yin S, Gao B. Invariant NKT-cell activation induces neutrophil accumulation and hepatitis: opposite regulation by IL-4 and IFN- $\gamma$. Hepatology 2013; 58: 1474-1485.

74 Jeong WI, Gao B. Innate immunity and alcoholic liver fibrosis. $J$ Gastroenterol Hepatol 2008; 23: S112-S118.

75 Szabo G, Bala S. Alcoholic liver disease and the gut-liver axis. World J Gastroenterol 2010; 16: 1321-1329.

76 Szabo G, Mandrekar P, Petrasek J, Catalano D. The unfolding web of innate immune dysregulation in alcoholic liver injury. Alcohol Clin Exp Res 2011; 35: 782-786. 
77 Bertola A, Park O, Gao B. Chronic plus binge ethanol feeding synergistically induces neutrophil infiltration and liver injury in mice: a critical role for E-selectin. Hepatology 2013; 58: 1814-1823.

78 Minagawa M, Deng Q, Liu ZX, Tsukamoto H, Dennert G. Activated natural killer $T$ cells induce liver injury by Fas and tumor necrosis factor-alpha during alcohol consumption. Gastroenterology 2004; 126: 1387-1399.

79 Stoy S, Dige A, Sandahl TD, Laursen TL, Buus C, Hokland M et al. Cytotoxic T lymphocytes and natural killer cells display impaired cytotoxic functions and reduced activation in patients with alcoholic hepatitis. Am J Physiol Gastrointest Liver Physiol 2015; 308: G269-G276.

80 Gao B, Shah VH. Combination therapy: new hope for alcoholic hepatitis? Clin Res Hepatol Gastroenterol 2015; 39: S7-S11.

81 Ki SH, Park O, Zheng M, Morales-Ibanez O, Kolls JK, Bataller R et al. Interleukin-22 treatment ameliorates alcoholic liver injury in a murine model of chronic-binge ethanol feeding: role of signal transducer and activator of transcription 3. Hepatology 2010; 52: 1291-1300.

82 Michelotti GA, Machado MV, Diehl AM. NAFLD, NASH and liver cancer. Nat Rev Gastroenterol Hepatol 2013; 10: 656-665.

83 Rinella ME, Sanyal AJ. NAFLD in 2014: genetics, diagnostics and therapeutic advances in NAFLD. Nat Rev Gastroenterol Hepatol 2015; 12: 65-66.

84 Valenti L, Fracanzani AL, Fargion S. The immunopathogenesis of alcoholic and nonalcoholic steatohepatitis: two triggers for one disease? Semin Immunopathol 2009; 31: 359-369.

85 Tang ZH, Liang S, Potter J, Jiang X, Mao HQ, Li Z. Tim-3/galectin-9 regulate the homeostasis of hepatic NKT cells in a murine model of nonalcoholic fatty liver disease. J Immunol 2013; 190: 1788-1796.

86 Wolf MJ, Adili A, Piotrowitz K, Abdullah Z, Boege Y, Stemmer K et al. Metabolic activation of intrahepatic CD8+ T cells and NKT cells causes nonalcoholic steatohepatitis and liver cancer via cross-talk with hepatocytes. Cancer Cell 2014; 26: 549-564.

87 Tajiri K, Shimizu Y, Tsuneyama K, Sugiyama T. Role of liverinfiltrating CD3+CD56+ natural killer $T$ cells in the pathogenesis of nonalcoholic fatty liver disease. Eur J Gastroenterol Hepatol 2009; 21: 673-680.

88 Corrigan M, Hirschfield GM, Oo YH, Adams DH. Autoimmune hepatitis: an approach to disease understanding and management. Br Med Bull 2015; 114: 181-191.

89 Jaeckel E, Hardtke-Wolenski M, Fischer K. The benefit of animal models for autoimmune hepatitis. Best Pract Res Clin Gastroenterol 2011; 25: 643-651.

90 Mattner J. Natural killer T (NKT) cells in autoimmune hepatitis. Curr Opin Immunol 2013; 25: 697-703.

91 Lafdil F, Miller AM, Ki SH, Gao B. Th17 cells and their associated cytokines in liver diseases. Cell Mol Immunol 2010; 7: 250-254.

92 Lan RY, Salunga TL, Tsuneyama K, Lian ZX, Yang GX, Hsu W et al. Hepatic IL-17 responses in human and murine primary biliary cirrhosis. J Autoimmun 2009; 32: 43-51.

93 Santodomingo-Garzon T, Swain MG. Role of NKT cells in autoimmune liver disease. Autoimmun Rev 2011; 10: 793-800.

94 Hirschfield GM, Heathcote EJ, Gershwin ME. Pathogenesis of cholestatic liver disease and therapeutic approaches. Gastroenterology 2010; 139: 1481-1496.

95 Kita H, Naidenko OV, Kronenberg M, Ansari AA, Rogers P, He XS et al. Quantitation and phenotypic analysis of natural killer $T$ cells in primary biliary cirrhosis using a human CD1d tetramer. Gastroenterology 2002; 123: 1031-1043.

96 Lehuen A, Lantz O, Beaudoin L, Laloux V, Carnaud C, Bendelac A et al. Overexpression of natural killer $\mathrm{T}$ cells protects Valpha14Jalpha281 transgenic nonobese diabetic mice against diabetes. J Exp Med 1998; 188: 1831-1839.

97 Sprengers D, Sille FC, Derkow K, Besra GS, Janssen HL, Schott $\mathrm{E}$ et al. Critical role for CD1d-restricted invariant NKT cells in stimulating intrahepatic CD8 T-cell responses to liver antigen. Gastroenterology 2008; 134: 2132-2143.

98 Ye L, Wang X, Wang S, Wang Y, Song L, Hou W et al. CD56+ T cells inhibit hepatitis $C$ virus replication in human hepatocytes. Hepatology 2009; 49: 753-762.
99 Fisicaro P, Valdatta C, Boni C, Massari M, Mori C, Zerbini A et al. Early kinetics of innate and adaptive immune responses during hepatitis B virus infection. Gut 2009; 58: 974-982.

100 Webster GJ, Reignat S, Maini MK, Whalley SA, Ogg GS, King A et al. Incubation phase of acute hepatitis $B$ in man: dynamic of cellular immune mechanisms. Hepatology 2000; 32: 1117-1124.

101 Kimura K, Kakimi K, Wieland S, Guidotti LG, Chisari FV. Interleukin18 inhibits hepatitis $B$ virus replication in the livers of transgenic mice. J Virol 2002; 76: 10702-10707.

102 Dunn SE, Ousman SS, Sobel RA, Zuniga L, Baranzini SE, Youssef $\mathrm{S}$ et al. Peroxisome proliferator-activated receptor (PPAR) alpha expression in T cells mediates gender differences in development of T cell-mediated autoimmunity. J Exp Med 2007; 204: 321-330.

103 Malhi H, Gores GJ. Cellular and molecular mechanisms of liver injury. Gastroenterology 2008; 134: 1641-1654.

104 Vilarinho S, Ogasawara K, Nishimura S, Lanier LL, Baron JL. Blockade of NKG2D on NKT cells prevents hepatitis and the acute immune response to hepatitis B virus. Proc Natl Acad Sci USA 2007; 104: 18187-18192.

105 Sachdeva M, Chawla YK, Arora SK. Immunology of hepatocellular carcinoma. World J Hepatol 2015; 7: 2080-2090.

106 Bricard G, Cesson V, Devevre E, Bouzourene H, Barbey C, Rufer $\mathrm{N}$ et al. Enrichment of human CD4+ V(alpha)24/Nbeta11 invariant NKT cells in intrahepatic malignant tumors. J Immunol 2009; 182: 5140-5151.

107 Anson M, Crain-Denoyelle AM, Baud V, Chereau F, Gougelet A, Terris $\mathrm{B}$ et al. Oncogenic beta-catenin triggers an inflammatory response that determines the aggressiveness of hepatocellular carcinoma in mice. J Clin Invest 2012; 122: 586-599.

108 Miyagi T, Takehara T, Tatsumi T, Kanto T, Suzuki T, Jinushi M et al. CD1d-mediated stimulation of natural killer $T$ cells selectively activates hepatic natural killer cells to eliminate experimentally disseminated hepatoma cells in murine liver. Int J Cancer 2003; 106: 81-89.

109 Abboud G, Kaplowitz N. Drug-induced liver injury. Drug Safety 2007; 30: 277-294.

110 Martin-Murphy BV, Kominsky DJ, Orlicky DJ, Donohue Jr TM, Ju C. Increased susceptibility of natural killer T-cell-deficient mice to acetaminophen-induced liver injury. Hepatology 2013; 57: 1575-1584.

111 Eltzschig HK, Eckle T. Ischemia and reperfusion-from mechanism to translation. Nat Med 2011; 17: 1391-1401.

112 Chen GY, Nunez G. Sterile inflammation: sensing and reacting to damage. Nat Rev Immunol 2010; 10: 826-837.

113 Bamboat ZM, Ocuin LM, Balachandran VP, Obaid H, Plitas G, DeMatteo RP. Conventional DCs reduce liver ischemia/reperfusion injury in mice via IL-10 secretion. J Clin Invest 2010; 120: 559-569.

114 Datta G, Fuller BJ, Davidson BR. Molecular mechanisms of liver ischemia reperfusion injury: insights from transgenic knockout models. World J Gastroenterol 2013; 19: 1683-1698.

115 Kreisel D, Sugimoto S, Tietjens J, Zhu J, Yamamoto S, Krupnick AS et al. Bcl3 prevents acute inflammatory lung injury in mice by restraining emergency granulopoiesis. J Clin Invest 2011; 121: 265-276.

116 Haraguchi K, Takahashi T, Matsumoto A, Asai T, Kanda Y, Kurokawa $\mathrm{M}$ et al. Host-residual invariant NK T cells attenuate graft-versus-host immunity. J Immunol 2005; 175: 1320-1328.

117 Pillai AB, George TI, Dutt S, Teo P, Strober S, Host NKT. cells can prevent graft-versus-host disease and permit graft antitumor activity after bone marrow transplantation. J Immunol 2007; 178: 6242-6251.

118 Shaulov A, Yue S, Wang R, Joyce RM, Balk SP, Kim HT et al. Peripheral blood progenitor cell product contains Th1-biased noninvariant CD1d-reactive natural killer T cells: implications for posttransplant survival. Exp Hematol 2008; 36: 464-472.

119 Exley MA, Bigley NJ, Cheng O, Shaulov A, Tahir SM, Carter QL et al. Innate immune response to encephalomyocarditis virus infection mediated by CD1d. Immunology 2003; 110: 519-526.

120 Fausto N, Campbell JS, Riehle KJ. Liver regeneration. J Hepatol 2012; 57: 692-694.

121 Michalopoulos GK. Liver regeneration after partial hepatectomy: critical analysis of mechanistic dilemmas. Am J Pathol 2010; 176: 2-13. 
122 Van Sweringen HL, Sakai N, Tevar AD, Burns JM, Edwards MJ, Lentsch AB. CXC chemokine signaling in the liver: impact on repair and regeneration. Hepatology 2011; 54: 1445-1453.

123 Yin S, Wang H, Bertola A, Feng D, Xu MJ, Wang Y et al. Activation of invariant natural killer $\mathrm{T}$ cells impedes liver regeneration by way of both IFN-gamma- and IL-4-dependent mechanisms. Hepatology 2014; 60: 1356-1366.

$124 \mathrm{Wu}$ X, Sun R, Chen Y, Zheng X, Bai L, Lian Z et al. Oral ampicillin inhibits liver regeneration by breaking hepatic innate immune tolerance normally maintained by gut commensal bacteria. Hepatology 2015; 62: 253-264. (c) (1) () $\ominus$ This work is licensed under a Creative Commons Attribution-NonCommercial-NoDerivs 4.0 International License. The images or other third party material in this article are included in the article's Creative Commons license, unless indicated otherwise in the credit line; if the material is not included under the Creative Commons license, users will need to obtain permission from the license holder to reproduce the material. To view a copy of this license, visit http://creativecommons.org/licenses/by-nc-nd/4.0/ 